\begin{tabular}{|c|l|}
\hline Title & $\begin{array}{l}\text { Two-Dimensional Crystals of A lkanes Formed on A u(111) Surface in Neat Liquid : Structural Investigation by } \\
\text { Scanning Tunneling Microscopy }\end{array}$ \\
\hline Author(s) & Y amada, R.; Uosaki, K. \\
\hline Citation & $\begin{array}{l}\text { Journal of Physical Chemistry B, 104(25), 6021-6027 } \\
\text { https:/doi.org/10.1021/jp994061z }\end{array}$ \\
\hline Issue Date & 2000-06-29 \\
\hline Doc URL & http://hdl.handle.net/2115/50237 \\
\hline Type & article \\
\hline File Information & JPCB104_25_6021-6027.pdf \\
\hline
\end{tabular}

Instructions for use 


\title{
Two-Dimensional Crystals of Alkanes Formed on Au(111) Surface in Neat Liquid: Structural Investigation by Scanning Tunneling Microscopy
}

\author{
R. Yamada and K. Uosaki* \\ Physical Chemistry Laboratory, Division of Chemistry, Graduate School of Science, Hokkaido University, \\ Sapporo 060-0810, Japan
}

Received: November 16, 1999; In Final Form: February 6, 2000

\begin{abstract}
In situ scanning tunneling microscopy revealed the formation of the two-dimensional (2D) crystals of $n$-alkanes $\left(\mathrm{C}_{n} \mathrm{H}_{2 n+2}, n=12-17\right)$ on a $\mathrm{Au}(111)$ surface in neat liquid at room temperature. The molecules were adsorbed on the gold surface with their molecular axis parallel to the surface plane. The molecular rows of even- and odd-numbered alkanes ran in the nearest-neighbor $(\mathrm{NN})$ atomic direction and the next-nearest-neighbor atomic direction of the gold surface, respectively. The molecular axis was oriented close to the $\mathrm{NN}$ direction of the gold surface in both odd- and even-numbered alkanes. Although there are two NN directions with respect to the direction of the bridging row of the herringbone structure due to the reconstruction of the $\mathrm{Au}(111)$ surface with crossing angles of $30^{\circ}$ and $90^{\circ}$, the molecular axis was preferentially oriented in the NN direction with a crossing angle of $30^{\circ}$. The $2 \mathrm{D}$ crystal of alkanes was not formed on the iodine-modified $\mathrm{Au}(111)$ surface, confirming that the molecule-substrate interaction played an important role in forming the $2 \mathrm{D}$ crystal of alkanes.
\end{abstract}

\section{Introduction}

Organic thin films of single molecular thickness at the solid/ liquid interface play important roles in many phenomena such as crystal growth, lubrication, wetting, and chemical reactions. In addition, formation of a well-ordered molecular layer on the surface is a key step in the construction of molecular devices and self-assembly (SA) and the Langmuir-Blodgett (LB) technique have been developed for this purpose. ${ }^{1}$ It is essential to understand the nature of the interaction between molecules and surfaces for the advanced design of the molecular layer. $n$-Alkanes are the simplest but very important molecules because they form the basis of lipids, surfactants, liquid crystals, and polymers. The interaction between the alkyl chain and the substrate as well as alkyl chains is also known to play important roles in the SA mechanism, ${ }^{2,3}$ and it is important to investigate the interaction between alkanes and metal surfaces.

The adsorption of the alkane on a metal surface was studied under UHV conditions. Firment and Somorjai showed that the alkanes formed ordered monolayers on $\operatorname{Pt}(111)^{4}$ and $\operatorname{Ag}(111)^{5}$ under UHV conditions by low-energy electron diffraction (LEED). In addition, the physisorption of alkanes has been studied on $\mathrm{Au}(111),{ }^{6} \mathrm{Pt}(111),{ }^{7,8} \mathrm{Pt}(110),{ }^{9} \mathrm{Ir}(110),{ }^{10} \mathrm{Cu}(100),{ }^{11}$ $\mathrm{Ru}(001),{ }^{12}$ and $\mathrm{Cu}(111),{ }^{13}$ under UHV conditions. However, the local arrangement of the alkanes on a metal surface has not been investigated in contrast to numerous reports of alkane adlayers on graphite at the solid/liquid interface, ${ }^{14-21}$ although studies using molecular dynamics ${ }^{12,22-27}$ and infrared spectroscopy ${ }^{28-32}$ under UHV conditions have been carried out after the reports by Firment and Somorjai. Furthermore, the structure of the alkane/metal interface in solution was not investigated. The formation of an ordered layer of the alkanes at the solid/ liquid interface was expected from the solvation force measurement ${ }^{33}$ which showed an oscillational feature when two surfaces were close to the short separation distance ( $\sim$ nanometers $)$. A molecular dynamics study of the confined organic films showed the periodic density profile of alkanes in a direction normal to the surface plane, ${ }^{34}$ supporting the results of the force measurement. The density profile normal to the surface plane may be influenced by the two-dimensional order of the alkanes on the surface. There is, however, no direct structural information on the two-dimensional order of the alkane layer on the surface except for our recent communication on the formation of a twodimensional crystal of alkanes on a $\mathrm{Au}(111)$ surface in neat alkane liquid, i.e., above their melting point. ${ }^{35}$

In this paper, we report a further detailed investigation on the structure of the 2D crystals of alkanes with various chain lengths on a $\mathrm{Au}(111)$ surface in a neat liquid.

\section{Experimental Section}

All chemicals $\left(\mathrm{C}_{n} \mathrm{H}_{2 n+2}, n=12-17\right)$ were purchased from Tokyo Chemical Industry (purity $>98 \%$ ) and were used without further purification. The $\mathrm{Au}(111)$ facet of a single crystalline bead, which was prepared by the Clavilier's method, ${ }^{36}$ was used as a substrate. The Au single crystalline bead was fixed on a $\mathrm{Pt}$ sheet and placed in an STM cell after a flame-annealing treatment. The iodine modification was carried out by immersing the gold substrate in a $5 \mathrm{mM}$ aqueous solution of KI for several minutes. The STM measurements were carried out using a PicoSPM (Molecular Imaging) controlled by a Nanoscope E (Digital Instruments) controller in a homemade cell in $\mathrm{Ar}$ atmosphere. The STM tip was made of a $\mathrm{Pt} / \mathrm{Ir}$ (8:2) wire sharpened by mechanical cutting. A small amount of alkane liquid was put in the cell, and STM measurements were carried out in a thin layer of neat alkanes at room temperature $(\sim 25$ ${ }^{\circ} \mathrm{C}$ ). Typical imaging conditions are $50 \mathrm{mV}$ in bias voltage and $20 \mathrm{pA}$ in tunneling current. The error of a measured distance was within $5 \%$.

\section{Results and Discussion}

Figures 1 show the STM images of a $\mathrm{Au}(111)$ surface obtained in dodecane $\left(\mathrm{C}_{12} \mathrm{H}_{26}: \mathrm{C}_{12}\right.$, a and $\left.\mathrm{a}^{\prime}\right)$, tridecane $\left(\mathrm{C}_{13} \mathrm{H}_{28}\right.$ : 

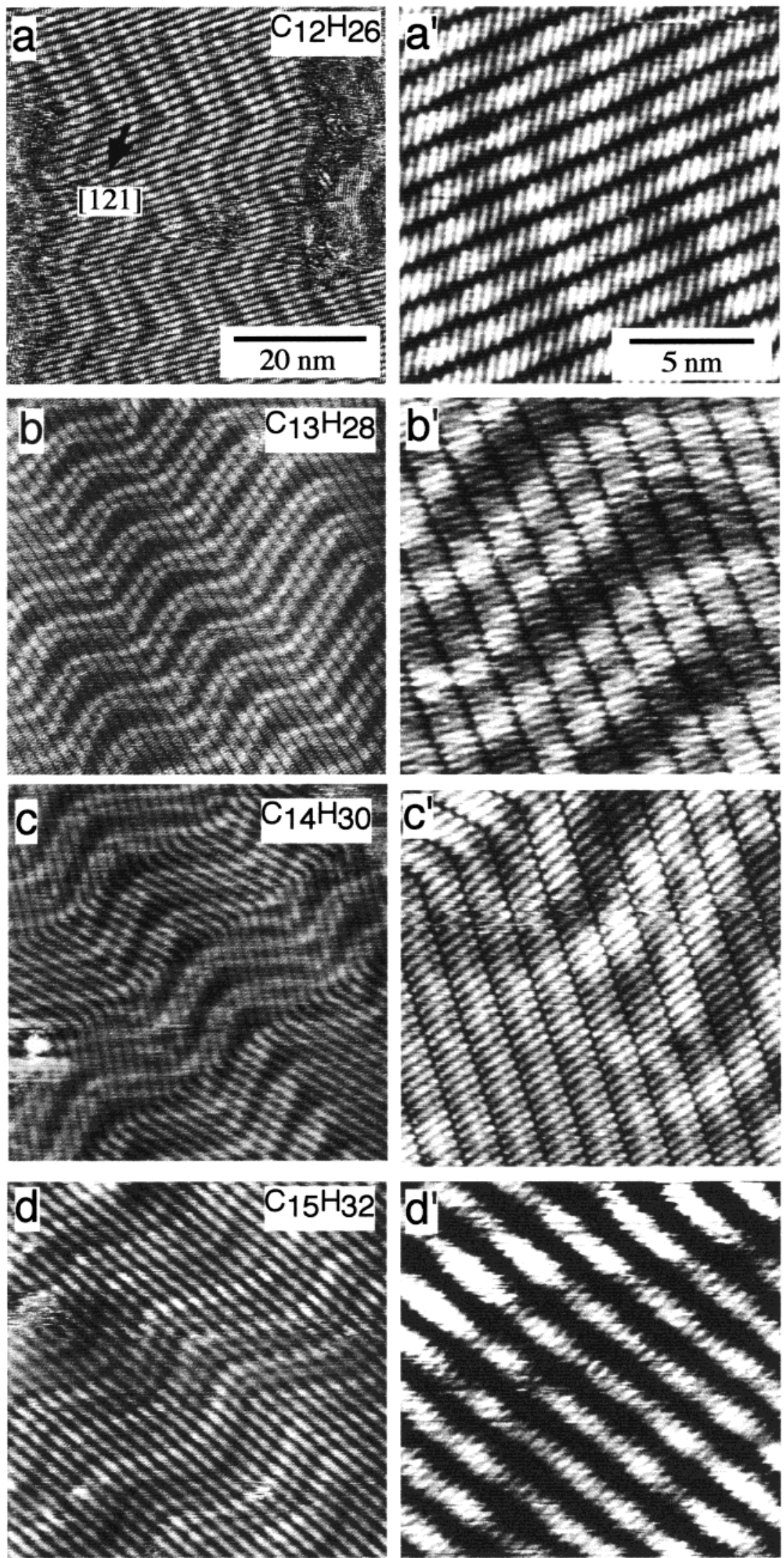

$\mathrm{C}_{13}, \mathrm{~b}$ and $\left.\mathrm{b}^{\prime}\right)$, tetradecane $\left(\mathrm{C}_{14} \mathrm{H}_{30}: \mathrm{C}_{14}, \mathrm{c}\right.$ and $\left.\mathrm{c}^{\prime}\right)$, pentadecane $\left(\mathrm{C}_{15} \mathrm{H}_{32}: \mathrm{C}_{15}, \mathrm{~d}\right.$ and $\left.\mathrm{d}^{\prime}\right)$, hexadecane $\left(\mathrm{C}_{16} \mathrm{H}_{34}: \mathrm{C}_{16}\right.$, e and $\left.\mathrm{e}^{\prime}\right)$, and heptadecane $\left(\mathrm{C}_{17} \mathrm{H}_{36}: \mathrm{C}_{17}\right.$, $\mathrm{f}$ and $\left.\mathrm{f}^{\prime}\right)$. The paired bright rows forming the herringbone structure indicated by an arrow in Figure 1a were observed in all the images. The row direction changed in every $10-15 \mathrm{~nm}$. This herringbone structure is very similar to the one observed on the reconstructed $\mathrm{Au}(111)$

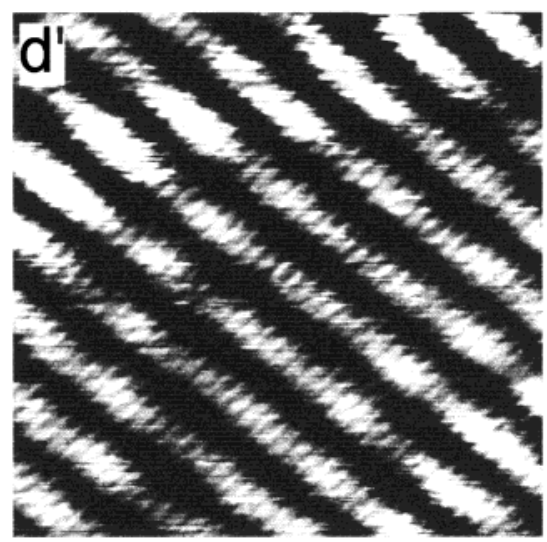

surface. ${ }^{37}$ The $\mathrm{Au}(111)$ reconstruction consists of a uniaxial compression of the surface atoms by ca. $4.5 \%$ in one of the three [110] directions and the registry of the surface atoms varies between hollow sites of fcc and hcp stacking to fit 23 atoms in 22 atomic spacings. The transitional region between the fcc and hcp stacking region is called bridging regions, which are elevated with respect to the fcc and hcp stacking regions, and 

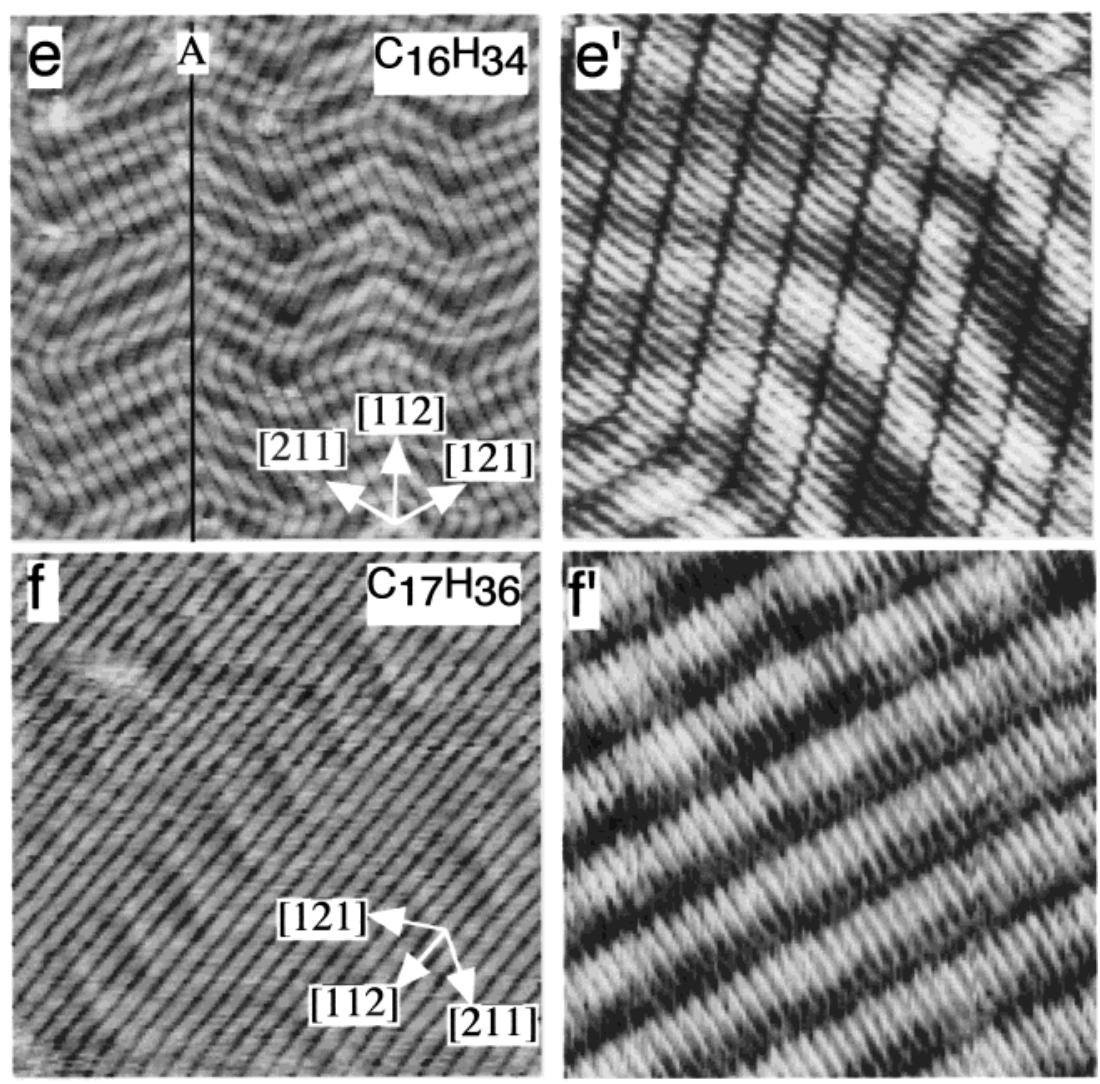

Figure 1. STM images of a $\mathrm{Au}(111)$ surface obtained in $\mathrm{C}_{12}$ (a and $\left.\mathrm{a}^{\prime}\right), \mathrm{C}_{13}$ (b an b'), $\mathrm{C}_{14}\left(\mathrm{c}\right.$ an $\left.\mathrm{c}^{\prime}\right), \mathrm{C}_{15}\left(\mathrm{~d}\right.$ and $\left.\mathrm{d}^{\prime}\right), \mathrm{C}_{16}\left(\mathrm{e}\right.$ and $\left.\mathrm{e}^{\prime}\right)$, and $\mathrm{C}_{17}$ (f and $\mathrm{f}^{\prime}$ ).

forms paired rows directed in the $[1 \overline{2} 1]$ direction. Thus, the reconstruction is denoted as $n \times \sqrt{3}$ structure $(n \sim 22)$. In addition, there is a regular alternation of the direction of the rows in every $\sim 15 \mathrm{~nm}$, resulting in a formation of the herringbone pattern. The features of the paired bright rows observed in Figure 1 were in good agreement with those of the reconstructed $\mathrm{Au}(111)$ surfaces. We, therefore, concluded that the $\mathrm{Au}(111)$ surface was reconstructed under the present experimental conditions.

First, let us discuss the structure observed in $\mathrm{C}_{16}$ in detail (Figure 1, e and $\mathrm{e}^{\prime}$ ). The image of lower magnification (Figure $1 \mathrm{e}, 50 \times 50 \mathrm{~nm}^{2}$ ) revealed a row structure forming a herringbone running in the vertical direction of the image in addition to the structure due to the reconstruction of the $\mathrm{Au}(111)$ surface running in the lateral direction of the image. The magnified image $\left(15 \times 15 \mathrm{~nm}^{2}\right)$ shown in Figure 1e' revealed that the row structure consisted of $2.2 \mathrm{~nm}$ long rods which were separated from each other by ca. $0.43 \mathrm{~nm}$. These values were comparable to the length $(2.2 \mathrm{~nm})$ and width $(0.45 \mathrm{~nm})$ of a $\mathrm{C}_{16}$ molecule, respectively, in the all-trans conformation. Thus, one can conclude that the $\mathrm{C}_{16}$ molecules lay on the $\mathrm{Au}(111)$ surface with their molecular axis parallel to the surface plane and formed a two-dimensional (2D) crystal. The corrugation amplitude was less than $0.05 \mathrm{~nm}$. It was highly dependent on the tip resolution but not on the tunneling conditions. The molecular row ran close to the [011], i.e., the nearest-neighbor $(\mathrm{NN})$ direction of the $\mathrm{Au}(111)$ surface. The molecular axis was also oriented close to the NN direction of the gold atoms because the angle formed by the molecular axis and the molecular row direction was ca. $60^{\circ}-65^{\circ}$. The molecular rows forming straight line and the herringbone were observed in $\mathrm{C}_{12}$ (Figure 1a) and $\mathrm{C}_{14}$ (Figure 1c), respectively. The direction of the molecular row was one of the NN directions in both cases. The direction of the molecular row of $\mathrm{C}_{14}$ and $\mathrm{C}_{16}$ changed by ca. $120^{\circ}$ every $\sim 18 \mathrm{~nm}$, although there were cases when molecular row was straight over $50 \mathrm{~nm}$. The origin of the herringbone structure of the $2 \mathrm{D}$ crystal of alkanes will be discussed later. The magnified image $\left(15 \times 15 \mathrm{~nm}^{2}\right)$ of the gold surface in $\mathrm{C}_{12}$ and $\mathrm{C}_{14}$, (Figure $1, a^{\prime}$ and $c^{\prime}$ ) showed the identical molecular arrangement as to that observed in $\mathrm{C}_{16}$, except that the lengths of the rods were 1.6 and $2.0 \mathrm{~nm}$ for $\mathrm{C}_{12}$ and $\mathrm{C}_{14}$, respectively. In the case of $\mathrm{C}_{12}$, there were disordered region or one-dimensional ordered regions (right side of the image) on the surface. Although this seemed to indicate that the melting point of the $2 \mathrm{D}$ crystal of $\mathrm{C}_{12}$ was close to the room temperature, detailed analysis under precious temperature control should be carried out to clarify this point.

The structure of the reconstructed $\mathrm{Au}(111)$ surface also affected the orientation of the alkanes. In all the cases, the molecular axis was preferentially oriented close to the $\mathrm{NN}$ direction which was tilted by $30^{\circ}$ with respect to the direction of the bridging row of gold reconstruction although there is another NN direction which crosses the direction of the bridging row by $90^{\circ}$ (Figure 2, a and b; we refer to the former and the latter as $\mathrm{NN}(30)$ and $\mathrm{NN}(90)$, respectively). The influence of the reconstruction of $\mathrm{Au}(111)$ surface on the structure of the 2D crystal of alkanes was apparent in the image shown in Figure 3 which was obtained in $\mathrm{C}_{16}$. The domain boundary of the molecular rows was formed following to the domain structure of the herringbone structure of the gold surface (see the center of the figure). On the contrary, the domain of the molecular row continued over the step on the gold substrate when the domain of the herringbone structure also continued beyond the step. The preferential orientation of the molecular axis to NN(30) can be explained by considering the corrugation of the gold surface. The corrugation of the gold surface is less in NN(30) (Figure 2a) than that in $\mathrm{NN}(90)$ (Figure 2b), and it should be unfavorable to adapt the molecular skeleton to $\mathrm{NN}(90)$. 
a

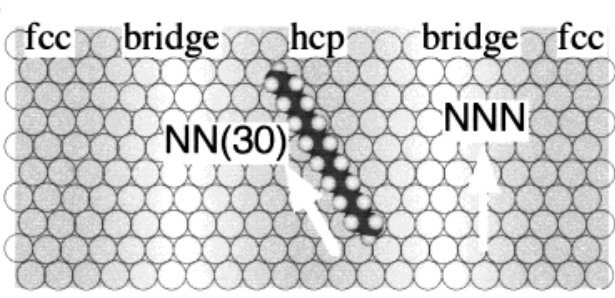

b

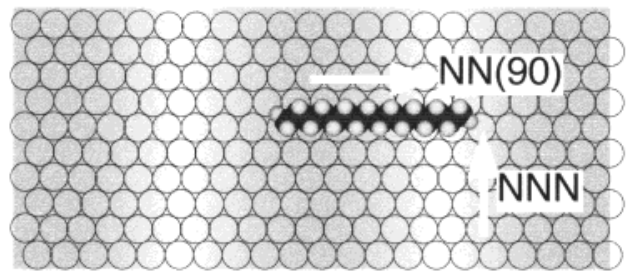

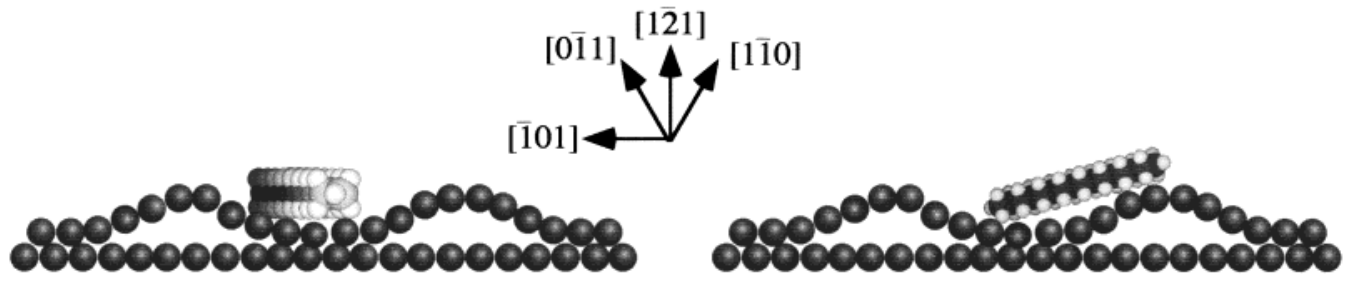

Figure 2. Schematic model of the reconstructed gold surface and the relative arrangement of alkanes: (a) $\mathrm{NN}(30)$ and (b) $\mathrm{NN}(90)$.

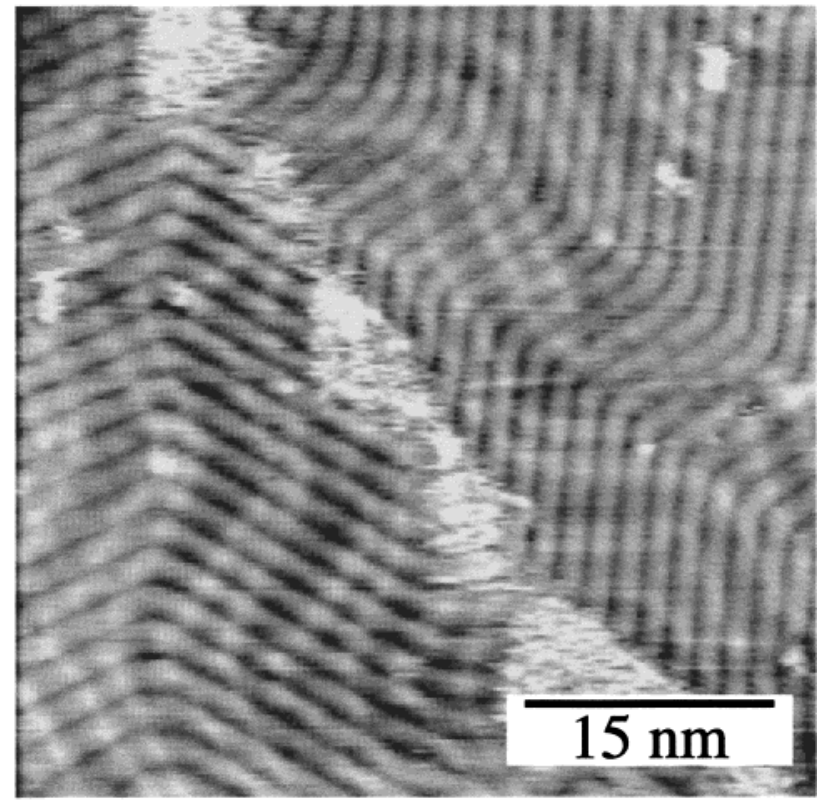

Figure 3. An STM image of a $A u(111)$ surface in $C_{16}$ which shows the domain boundary of the alkane structure and the herringbone of the gold surface.

Figure 4 shows an magnified STM image of the region where the direction of the molecular row changed observed in $\mathrm{C}_{14}$. The detailed analyses of the STM image revealed that the direction of the molecular axis slightly changed by $12^{\circ}-15^{\circ}$ when the direction of the molecular row changed. If the molecular axis is just along the [1 10 ] direction, the direction of the molecular axis should be the same or crossed by $60^{\circ}$ from each other when the direction of the molecular row changed. The molecular axis was, therefore, tilted slightly from the NN direction, probably by half of the angle which was observed in Figure 4 , i.e., $6^{\circ}-7.5^{\circ}$, and the molecular arrangement is incommensurate with the gold surface.

The $2 \mathrm{D}$ crystals but with a different molecular row structure were observed when the STM measurement was carried out in the odd-numbered alkanes, $\mathrm{C}_{13}$ (Figure 1, b and b'), $\mathrm{C}_{15}$ (Figure $1, \mathrm{~d}$ and $\mathrm{d}^{\prime}$ ), and $\mathrm{C}_{17}$ (Figure $1, \mathrm{f}$ and $\mathrm{f}^{\prime}$ ). Let us discuss the structure observed in $\mathrm{C}_{17}$ in detail (Figure $1, \mathrm{f}$ and $\mathrm{f}^{\prime}$ ). In contrast to the case of the even-numbered alkanes, the straight rows ran in the [1-12], i.e., the next-nearest neighbor (NNN), direction of the gold surface (Figure 1f). The magnified image shown in Figure $1 f^{\prime}$ revealed that the row structure consisted of rods of $2.3 \mathrm{~nm}$ length and the angle formed by the molecular row and

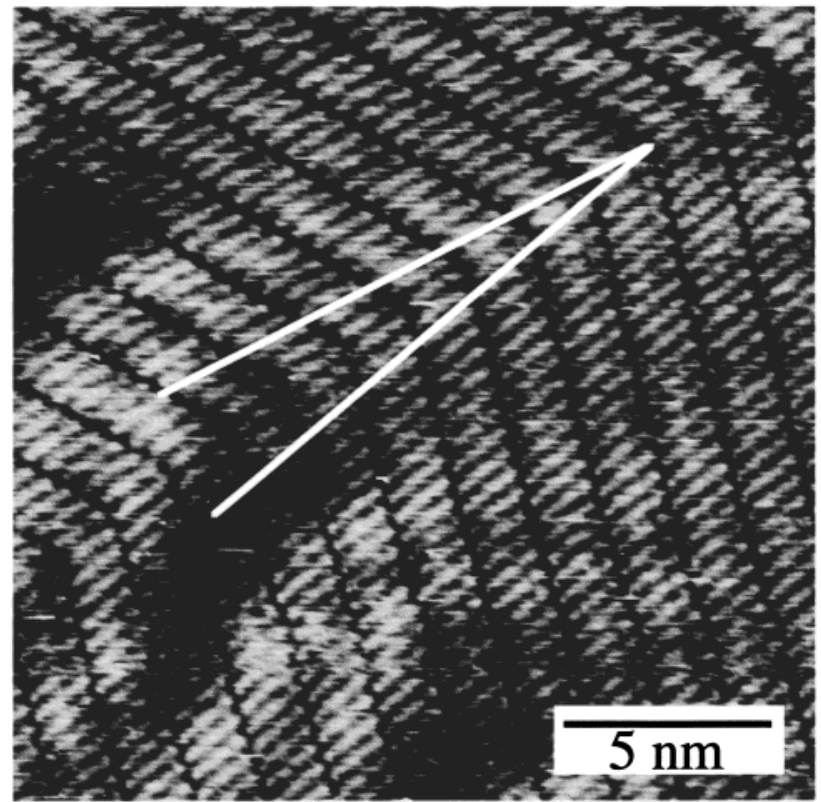

Figure 4. An STM image of a $\mathrm{Au}(111)$ surface in $\mathrm{C}_{14}$.

TABLE 1: Summary of the Structure of the 2D Crystal of Alkanes on a Au(111) Surface

\begin{tabular}{ccc}
\hline & \multicolumn{2}{c}{ direction of the } \\
\cline { 2 - 3 }$n$ (in $\left.\mathrm{C}_{n} \mathrm{H}_{2 n+2}\right)$ & molecular row & molecular axis \\
\hline 12 & $\mathrm{NN}$ & $\mathrm{NN}$ \\
13 & $\mathrm{NNN}$ & $\mathrm{NN}$ \\
14 & $\mathrm{NN}$ & $\mathrm{NN}$ \\
15 & $\mathrm{NNN}$ & $\mathrm{NN}$ \\
16 & $\mathrm{NN}$ & $\mathrm{NN}$ \\
17 & $\mathrm{NNN}$ & $\mathrm{NN}$
\end{tabular}

molecular axis was ca. $90^{\circ}$, indicating that the molecular axis was oriented in the [1 $1 \overline{1} 0]$ direction, i.e., the $\mathrm{NN}$ direction of the gold surface. The magnified image of the gold surface in other odd-numbered alkanes, $\mathrm{C}_{13}$ and $\mathrm{C}_{15}$, showed an identical molecular arrangement to that observed in $\mathrm{C}_{17}$ except for the molecular lengths, which were 1.8 and $2.4 \mathrm{~nm}$ in $\mathrm{C}_{13}$ and $\mathrm{C}_{15}$, respectively, as shown in Figure 1, $b^{\prime}$ and d'.

The above results clearly showed that $2 \mathrm{D}$ crystals of alkanes were formed on the $\mathrm{Au}(111)$ surface in neat liquid and that their structure was odd-even dependent. As summarized in Table 1 , the molecular row ran in the NN and the NNN direction when the carbon number was even and odd, respectively, while the molecular axis was oriented close to the $\mathrm{NN}$ direction regardless 
a

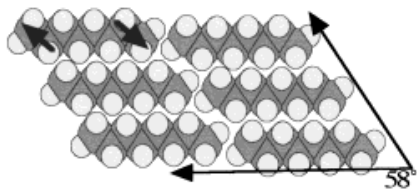

$a^{\prime}$

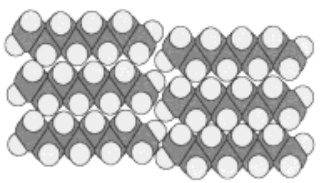

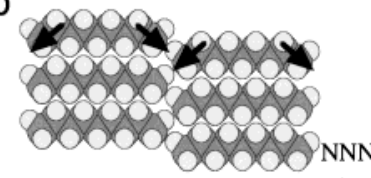

$b^{\prime}$

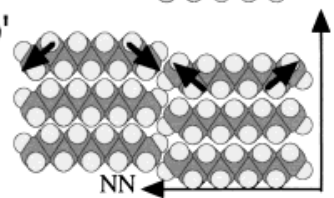

Figure 5. Proposed models of the $2 \mathrm{D}$ crystal of even (a and $\mathrm{a}^{\prime}$ ) and odd ( $b$ and $\left.b^{\prime}\right)$ alkanes.

of the carbon number. Figure 5a,b shows the proposed model structures of the 2D crystals of even- and odd-numbered alkanes, respectively. These models were constructed on the basis of STM images and considering the structures of 2D crystals of alkanes on other metal surface previously reported under UHV conditions. The difference in the structure of the 2D crystal between the odd- and even-numbered alkanes may arise from the difference in the symmetry of the molecule which is determined by the direction of the terminal methyl groups as shown by arrows in Figure 5 (discussed later in detail). Considering the close-packing structure of the even-numbered alkanes, the two models can be constructed as shown in Figure 5 , a and a'. Apparently, the observed structure was similar to the model shown in Figure 5a. The molecular lattice shown in Figure 5a was formed probably because it was favorable for the molecular terminal to be arranged in the NN direction of the gold surface. A very similar structure was also observed in the $2 \mathrm{D}$ crystal of hexane on a $\operatorname{Ag}(111)$ surface in UHV. ${ }^{5}$ The two models were proposed for the $2 \mathrm{D}$ crystal of the oddnumbered alkanes as shown Figure 5, b and $b^{\prime}$. While all of the molecules orient in the same direction in the model shown in Figure $5 \mathrm{~b}$, the direction of the terminal methyl group of the molecules in the molecular row of the left-hand side is opposite to that in the neighboring molecular rows in the model shown in Figure $5 b^{\prime}$. It was impossible to decide which model was correct from the STM images. The models shown in Figure $5 b, b^{\prime}$ are identical to the structures of the 2D crystals of heptane on $\operatorname{Ag}(111)$ and $\mathrm{Pt}(111)$, respectively. Because the structure of the $2 \mathrm{D}$ crystals of the even-numbered alkanes on $\mathrm{Au}(111)$ was similar to that on $\operatorname{Ag}(111)$ and the atomic distance of the $\mathrm{Au}$ $(0.288 \mathrm{~nm})$ is almost identical to that of $\mathrm{Ag}$, the model shown in Figure $5 \mathrm{~b}$ seems to be more appropriate.

As mentioned before, the herringbone of the molecular rows were formed in the 2D crystals of the even-numbered alkanes (e.g., see Figure 1e). The formation of the herringbone may be explained as follows. The well-ordered herringbone structure of the reconstructed gold surface is considered to possess a mirror symmetry with respect to the plane perpendicular to the surface and formed by connecting the elbows of the herringbone structure in the [1 $\left.1 \overline{1}_{2}\right]$ direction indicated as a line A in Figure 1e. The direction of the molecular axis is restricted to that close to the $\mathrm{NN}(30)$ direction and, as a result, the directions of the molecular row available for the even-numbered alkanes are those crossing the line $\mathrm{A}$ by $\pm 30^{\circ}$. If the $2 \mathrm{D}$ crystal of alkanes consisted of the molecular row of only one direction, the 2D crystal has an anisotropic strain when it is adapted to the reconstructed $\mathrm{Au}(111)$ surface. The molecular row in the two directions should equivalently appear to cancel the strain in a macroscopic view. The regular turn of the molecular row may indicate the formation of the stress domain which is formed when anisotropic stress with a long-range interaction exists. ${ }^{38-40}$ The direction of the molecular row of the odd-numbered alkanes

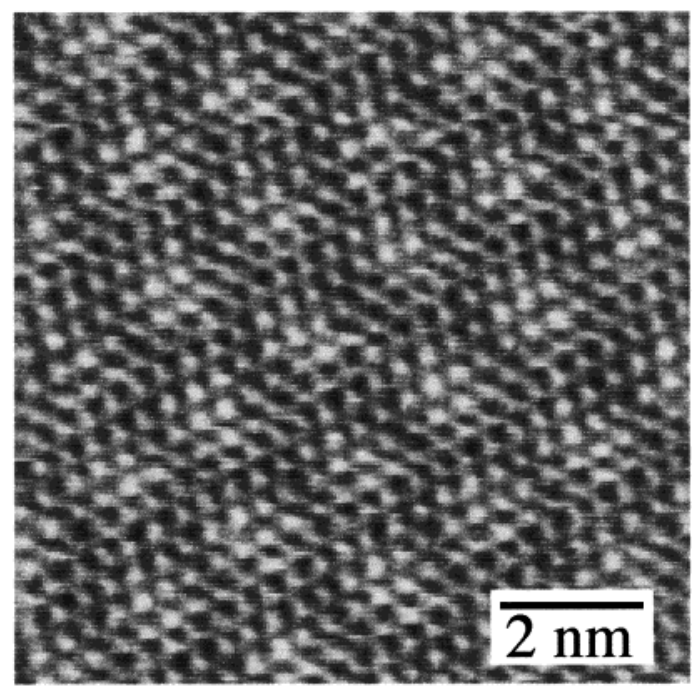

Figure 6. An STM image of an $\mathrm{I}-\mathrm{Au}(111)$ surface in $\mathrm{C}_{16}$.

was parallel to [1 $1 \overline{1} 2]$, i.e., line $\mathrm{A}$, and the structure of the $2 \mathrm{D}$ crystal possesses a common symmetric axis with the gold substrate. As a result, a straight molecular row was formed.

The STM investigation of the iodine-modified $\mathrm{Au}(111)$ surface (I-Au(111)) in $\mathrm{C}_{16}$ was carried out to clarify the effect of the substrate. Figure 6 shows an STM image which shows the spots in a hexagonal arrangement $0.46 \mathrm{~nm}$ apart with a longrange hexagonal height variation. These features were similar to the rotated hexagonal structure of iodine on $\mathrm{Au}(111) .^{41,42}$ There were no structures which corresponded to alkane adlayers. The absence of the alkane adlayer is explained in two ways. One reason is that the alkanes were not adsorbed on the surface, and the other is that the alkanes were actually adsorbed on the surface but the STM investigation itself swept them away. Although these two cases are indistinguishable from the STM measurement, it is obvious that the adsorption of the alkanes was weaker on the $\mathrm{I}-\mathrm{Au}(111)$ surface than that on a bare $\mathrm{Au}$ (111) surface. It is interesting to compare the present results with the reports of Ogaki et al. ${ }^{43}$ in which ordered layers of organic molecules such as porphyrin and crystal violet were easily formed on iodine-covered $\mathrm{Au}, \mathrm{Ag}$, and $\mathrm{Pt}$ surfaces, although these molecules formed disordered structures on the bare metal surfaces. The formation of the disordered structure on the bare surface should indicate that the surface diffusion and reorientation of the molecules, which were essential for the self-ordering process of the molecules, were prohibited due to the strong attractive interactions between the molecules and the substrates. Ogaki et al. suggested that interaction between the molecules and the surface was weakened and became a physical nature on the iodine layer, resulting in the formation of ordered molecular structures. In the present case, the interaction between the alkanes and the substrate was weak even on the bare gold and became too weak to fix the alkanes on the iodine-modified surface.

The structure of the alkane adlayer was investigated by lowenergy electron diffraction on $\mathrm{Pt}(111),{ }^{4} \mathrm{Ag}(111),{ }^{5}$ and $\mathrm{Cu}(111)^{13}$ as summarized in Table 2 . The odd-even effect on the alkane adlayer was observed on all substrates although the structure was dependent on the substrate. Although the angle formed by the molecular axis and the molecular row direction was $90^{\circ}$ regardless of the number of carbons on $\operatorname{Pt}(111)$, the number of molecules in a unit cell was higher than that of even numbered alkanes. On the other hand, the angle formed by the molecular axis and the molecular row direction on $\operatorname{Ag}(111)$ was about $60^{\circ}$ and $90^{\circ}$ for the even- and odd-numbered alkanes, respec- 
TABLE 2: Summary of the Structure of the 2D Crystal of Alkanes

\begin{tabular}{llclll}
\hline & & \multicolumn{2}{c}{$\begin{array}{c}\text { angle formed by } \\
\text { molecular axis and row }\end{array}$} & \\
\cline { 3 - 4 } substrate & \multicolumn{1}{c}{ lattice } & odd & even & ref \\
\hline $\operatorname{Pt}(111)$ & commensurate & 90 & 90 & 2 & \\
$\operatorname{Ag}(111)$ & incommensurate & 90 & about 60 & 3 \\
$\mathrm{Cu}(111)$ & commensurate & 90 & 60 & 11 \\
$\mathrm{Au}(111)$ & incommensurate? & 90 & about 60 & present study
\end{tabular}

tively. The herringbone structure of octane $(n=8)$ was observed on $\mathrm{Cu}(111)$, while the molecular axis of nonane $(n=9)$ was perpendicular to the molecular row. The molecular axis was oriented to the $\mathrm{NN}$ direction in all cases. The preferential orientation of the molecular axis in the NN direction was consistent with the molecular dynamics simulation which showed that diffusion and adsorption along the NN direction were favorable on $\operatorname{Pt}(111){ }^{23,24}$ The local structure of the 2D crystals of alkanes was investigated by STM on graphite in solution; the molecular arrangement was commensurate and the angle between the molecular row and the molecular axis was 90 in both odd ${ }^{20,21}$ and even ${ }^{14-19}$ alkane 2D crystals on the graphite. The molecular arrangement was commensurate on graphite, $\mathrm{Pt}(111)$, and $\mathrm{Cu}(111)$ but was incommensurate on $\mathrm{Ag}$ (111) and $\mathrm{Au}(111)$ surface.

Whether the lattice of alkanes is commensurate or incommensurate should depend on the adsorption energy and adaptation of atomic corrugation with the $\mathrm{C}-\mathrm{C}-\mathrm{C}$ zigzag structure. For example, the length of the $\mathrm{C}-\mathrm{C}-\mathrm{C}$ zigzag, $0.254 \mathrm{~nm}$, is close to the atomic spacing of graphite, $0.246 \mathrm{~nm}$ (space between hollows), and the carbon skeleton can be fitted to the surface lattice. The difference between the NN atomic distance and the $\mathrm{C}-\mathrm{C}-\mathrm{C}$ zigzag length becomes larger on the $\mathrm{Ag}(111)$ and $\mathrm{Au}-$ (111) surfaces where the NN atomic distances are 0.288 and $0.289 \mathrm{~nm}$, respectively, than that on the $\mathrm{Pt}(111)$ and $\mathrm{Cu}(111)$ surface where the $\mathrm{NN}$ atomic distances are 0.277 and 0.256 $\mathrm{nm}$, respectively. In addition, the atomic distance in the NNN direction, which is perpendicular to the molecular axis, should be considered because this distance is related to the distance between the molecules. The $\mathrm{Cu}(111)$ surface is expected to be the most favorable surface to form the commensurate alkane $2 \mathrm{D}$ crystals in this respect as well because the NNN atomic distance of the $\mathrm{Cu}(111), 0.443 \mathrm{~nm}$, is the closest to the width of alkane, $0.45 \mathrm{~nm}$, among the (111) surfaces of the metals mentioned here.

It should be noted that the symmetry of the atomic arrangement was broken on the reconstructed $\mathrm{Au}(111)$ surface. The surface is compressed by $4.5 \%$ in the direction perpendicular to the bridge row (we have defined this direction as $\mathrm{NN}(90)$, see Figure 2). The NN and NNN atomic distance of the Au(111) surface in the compressed direction is 0.277 and 0.486 $\mathrm{nm}$, respectively. The adsorption of alkanes with molecular axis along $\mathrm{NN}(90)$ is expected to be more favorable if one considers that the NN atomic distance in this direction is closer to the $\mathrm{C}-\mathrm{C}-\mathrm{C}$ zigzag length than that in $\mathrm{NN}(30)$. The experimental results presented here, however, do not agree with this expectation. The molecular adsorption in $\mathrm{NN}(90)$ should be prevented by the surface corrugation in $\mathrm{NN}(90)$ due to the reconstruction as mentioned before. The NNN atomic distance in the compressed direction is closer to the width of alkanes than that in the uncompressed direction, and the molecular stacking in this direction is expected to be favorable. Therefore, the adsorption with molecular axis along $\mathrm{NN}(30)$ is expected to be formed.

The adsorption energy of the alkanes on a metal surface has been measured on various metals under UHV conditions. ${ }^{6-12}$
The desorption energy was proportional to numbers of the methylene, ca. $6.5 \mathrm{~kJ} / \mathrm{mol}$ per methylene unit. The larger adsorption energy on the $\operatorname{Pt}(111)$ is expected due to the higher electronic density around the Fermi level of Pt because the van der Waals interaction between the metal surface and a helium atom was shown to be roughly proportional to the electronic density. ${ }^{44}$ Actually, the desorption energy of the alkanes on Pt(111) surface is larger by ca. $5 \mathrm{~kJ} / \mathrm{mol}$ than that on $\mathrm{Au}(111) .{ }^{6-8}$ Thus, the origin of the commensurate $2 \mathrm{D}$ crystal formation on $\mathrm{Pt}(111)$ may be due to both strong adsorption energy and lattice fitness. Although the desorption energy of alkanes on $\mathrm{Cu}(111)$ was not investigated, that on $\mathrm{Cu}(100)$ was lower than that on $\mathrm{Au}(111)$. Thus, the origin of the commensurate 2D crystal formation on $\mathrm{Cu}(111)$ may be mainly attributed to the better lattice matching.

The odd-even effect has also been found in the structure of bulk single crystals of alkanes. ${ }^{45}$ The molecular axis is normal and tilted by $72^{\circ}$ to the layer plane formed by the alkanes when the number of carbons is odd ${ }^{46}$ and even, ${ }^{47}$ respectively. The odd-even effect on the single crystals of alkanes was explained by the rules shown by Kitagorodskii. ${ }^{48}$ The odd-numbered alkanes have an inversion center while the even-numbered alkanes have a mirror plane at the center of the molecule. The inversion center and the mirror plane, which coincides with the layer plane in a single crystal, should be retained in the crystal lattice to achieve a close-packing structure. The same consideration should be applied to the two-dimensional crystals of alkanes. The angle between the molecular row and the molecular axis is restricted to be $90^{\circ}$ when the carbon number is odd (Figure 5b), while it could be both tilted and $90^{\circ}$ when the carbon number is even. In the present case, the structure of the substrate should be one of the factors in determining the structure.

In conclusion, we observed the structure of the $2 \mathrm{D}$ crystal of alkanes on a $\mathrm{Au}(111)$ surfaces in neat liquids. The 2D crystalline structure of alkanes on the $\mathrm{Au}(111)$ surface showed odd-even effect. The angle between the molecular row and the molecular axis was perpendicular and ca. $60^{\circ}$ when the carbon number was odd and even, respectively, indicating that the moleculemolecule interaction is the dominant factor in determining the structure of the $2 \mathrm{D}$ crystal.

Acknowledgment. This work was partially supported by a Grant-in-Aid for Scientific Research on the Priority Area of "Electrochemistry of Ordered Interfaces" (09237101) from the Ministry of Education, Science, Sports, and Culture, Japan. R.Y. acknowledges the Japan Society for the Promotion of Science for a fellowship.

\section{References and Notes}

(1) Ulman, A. Introduction to Ultrathin Organic Films from Langmuir-Blodgett to Self-Assembly; Academic Press: San Diego, CA, 1991.

(2) Poirier, G. E.; Pylant, D. Science 1996, 272, 1145.

(3) Yamada, R.; Uosaki, K. Langmuir 1997, 13, 5219; 1998, 14, 855.

(4) Firment, L. E.; Somorjai, G. A. J. Chem. Phys. 1977, 66, 2901.

(5) Firment, L. E.; Somorjai, G. A. J. Chem. Phys. 1978, 69, 3940.

(6) Wetter, S. M.; Lavrich, D. J.; Cummings, T.; Bernasek, S. L.; Scoles, G. J. Phys. Chem. B 1998, 102, 9266.

(7) Arumainayagam, C. R.; Scgiifsm, G. R.; McMaster, M. C.; Madix, R. J. J. Phys. Chem. 1991, 95, 1041.

(8) McMaster, M. C.; Arumainayagam, C. R.; Madix, R. J. Chem. Phys. 1993, 177,461 .

(9) McMaster, M. C.; Schroeder, S. L. M.; Madix, R. J. Surf. Sci. 1993, 297, 253.

(10) Kang, H. C.; Mullins, C. B.; Weinberg, W. H. J. Chem. Phys. 1990, 92, 1397.

(11) Sexton, B. A.; Hughes, A. E. Surf. Sci. 1984, 140, 227. 
(12) Brand, J. L.; Arena, M. V.; Deckert, A. A.; Grorge, S. M. J. Chem. Phys. 1990, 92, 5136.

(13) Fuhrmann, D.; Gerlach, R.; Rubahn, H. G.,; Wöll, Ch. Surf. Sci. 1999, 424, 145 .

(14) Cyr, D. M.; Venkataraman, B.; Flynn, G. W.; Black, A.; Whitesides, G. M. J. Phys. Chem. 1996, 100, 13747.

(15) Hentschke, R.; Schümann, B. L.; Rabe, J. P. J. Chem. Phys. 1992, 96,6213 .

(16) Bucher, J. P.; Roeder, H.; Kern, K. Surf. Sci. 1993, 289, 370.

(17) Venkataraman, B.; Breen, J. J.; Flynn, G. W. J. Phys. Chem. 1995, 99,6608 .

(18) McGonigal, G. C.; Bernhardt, R. H.; Thomson, D. J. Appl. Phys. Lett. 1990, 57, 28.

(19) Watel, G.; Thibaudau, F.; Cousty, J. Surf. Sci. Lett. 1993, 281, 297.

(20) Claypool, C. L.; Faglioni, F.; Goddard III, W. A.; Gray, H. B.;

Lewis, N. S.; Marcus, R. A. J. Phys. Chem. B 1997, 101, 5978.

(21) Rabe, J. P.; Buchholz, S. Science 1991, 253, 424.

(22) Fichthorn, K. A.; Balan, P. G.; Chen, Y. Surf. Sci. 1994, 317, 37.

(23) Huang, D.; Chen, Y.; Fichthorn, K. A.; J. Chem. Phys. 1994, 101, 11021 .

(24) Raut, J. S.; Fichthorn, K. A. J. Chem. Phys. 1998, 108, 1626.

(25) Wang, J.-C.; Fichthorn, K. A. J. Chem. Phys. 1998, 108, 1653.

(26) Silverberg, M. J. Chem. Phys. 1993, 99, 9255.

(27) Landman, U.; Xia, T. K. Science 1993, 261, 1310.

(28) Demuth, J. E.; Ibach, H.; Lehwald, S. Phys. Rev. Lett. 1978, 40, 1044 .

(29) Chesters, M. A.; Gardner, P.; McCash, E. M. Surf. Sci. 1989, 209, $89 ; \mathbf{1 9 8 9}, 209,89$.

(30) Hostetler, M. J.; Manner, W. L.; Nuzzo, R. G.; Girolami, G. S. J. Phys. Chem. 1995, 99, 15269.

(31) Manner, W. L.; Bishop, A. R.; Girolami, G. S.; Nuzzo, R. G. J. Phys. Chem. B. 1998, 102, 8816.
(32) Manner, L. W.; Girolami, G. S.; Nuzzo, R. G. Langmuir 1998, 14, 1716

(33) Christenson, H. K.; Gruen, D. W. R.; Horn, R. G.; Israelachvili, J. N. J. Chem. Phys. 1987, 87, 1834. Gee, M. L.; Israelachvili, J. N. J. Chem. Soc., Faraday Trans. 1990, 86, 4049.

(34) Gao, J.; Luedtke, W. D.; Landman, U. J. Phys. Chem. B 1997, $101,4013$.

(35) Uosaki, K.; Yamada, R. J. Am. Chem. Soc. 1999, 121, 4090.

(36) Clavilier, J. J. Electroanal. Chem. 1980, 107, 211, 205.

(37) Wöll, Ch.; Chiang, S.; Wilson, R. J.; Lippel, P. H. Phys. Rev. B 1989, 39, 7988. Barth, J. V.; Brune, H.; Ertl, G.; Behm, R. J. Phys. Rev. B 1990, 42, 9307.

(38) Villain, J.; Gordon, M. B. Surf. Sci. 1983, 125, 1.

(39) Alerhand, O. L.; Vanderbilt, D.; Meade, R. D.; Joannopoulos, J. D. Phys. Rev. Lett. 1988, 61, 1973.

(40) Narasimhan, S.; Vanderbilt, D. Phys. Rev. Lett. 1992, 69, 1564.

(41) Haiss, W.; Sass, J. K.; Gao, X.; Weaver, M. J. Surf. Sci. Lett. 1992, $274,593$.

(42) Yamada, T.; Batina, N.; Itaya, K. Surf. Sci. 1995, 335, 204. Batina, N.; Yamada, T.; Itaya, K. Langmuir 1995, 11, 4568.

(43) Itaya, K. Prog. Surf. Sci. 1998, 58, 121. Ogaki, K.; Batina, N.; Kunitake, M.; Itaya, K. J. Phys. Chem. 1996, 100, 7185. Kunitake, M.; Akiba, U.; Batina, N.; Itaya, K. Langmuir 1997, 13, 1607.

(44) Zaremba, E.; Kohn, W. Phys. Rev. B 1977, 15, 1769.

(45) Small, D. M. The Physical Chemistry of Lipids From Alkanes to Phospholipids; Plenum Press: New York, 1986; Chapter 5.

(46) Denicolò, I.; Doucet, J.; Craievich, A. F. J. Chem. Phys. 1983, 78 1465 .

(47) Doucet, J.; Denicolò I.; Craievich, A. J. Chem. Phys. 1981, 75 1523

(48) Kitaigorodskii, A. I. Organic Chemical Crystallography; Consultants Bureau Enterprises: New York, 1961. 